\title{
PPGL em Diálogo - 45 anos: tradição e renovação
}

\author{
PPGL in Dialogue - 45 years: tradition and renovation \\ Maria da Glória Corrêa di Fanti \\ Pontifícia Universidade Católica do Rio Grande do Sul - Porto Alegre - Rio Grande do Sul - Brasil \\ Ana Maria Lisboa de Mello \\ Pontifícia Universidade Católica do Rio Grande do Sul - Porto Alegre - Rio Grande do Sul - Brasil \\ Lilian Cristine Hübner \\ Pontifícia Universidade Católica do Rio Grande do Sul - Porto Alegre - Rio Grande do Sul - Brasil
}

$\mathrm{D}$ e 28 a 30 de outubro de 2015, em comemoração aos 45 anos, o Programa de Pós-Graduação em Letras (PPGL) da Pontifícia Universidade Católica do Rio Grande do Sul (PUCRS) acolheu, com satisfação, o DUO VII - Dialogue Under Occupation - evento internacional, interdisciplinar e itinerante, reunindo especialistas do Brasil e do exterior para refletirem sobre estudos relativos ao diálogo, a partir de três eixos temáticos: Diálogo em Perspectiva, Dilemas Interculturais e Expressão de Conflitos. Esse evento, integrando as áreas de concentração do PPGL - Linguística, Teoria da Literatura e Escrita Criativa - e as interfaces com diferentes campos do conhecimento, como Filosofia, Comunicação, Educação, Psicologia etc., justifica-se como um importante espaço de discussão entre estudiosos brasileiros e estrangeiros para aprofundar teorias e metodologias que iluminam estudos sobre os eixos temáticos. Também se justifica como um espaço de encontro entre pesquisadores para o desenvolvimento de trabalhos e possíveis parcerias futuras.

Nesse cenário comemorativo, elegemos o diálogo como tema central das reflexões, entrando em sintonia com o foco de debate do DUO VII. Aparentemente de simples compreensão, o diálogo é um conceito complexo e tem várias acepções nos estudos acadêmicos em Letras e Ciências Humanas. Diálogo, conflito ou impossibilidade de diálogo expressam-se no âmbito dos discursos escritos e nas relações interpessoais e intersociais. A existência do diálogo entre pessoas e grupos, de modo geral, exige abertura e sensibilidade para acolher a perspectiva do outro, disponibilidade para traçar objetivos comuns e superação de diferenças e impasses entre participantes do diálogo.

Sem desconsiderar as diferentes compreensões e a sua pertinência para as pesquisas nas Ciências Humanas, tomamos o conceito de diálogo a partir dos estudos do Círculo de Bakhtin para embasar a reflexão. No Dicionário de Linguística da Enunciação, dois verbetes, seguindo a teoria bakhtiniana, são cunhados para tratar do tema: diálogo e dialogismo. Embora seja possível conceituar no mesmo verbete diálogo e dialogismo, mostrando as particularidades de cada conceito, que mais se aproximam do que se distanciam, a abordagem em separado justificase por ressaltar o que é e o que não é diálogo para o Círculo. O diálogo, na obra referida, é definido como "propriedade constitutiva de todo discurso que pressupõe comunicação com outros discursos e o discurso do outro, independentemente da estrutura dos enunciados" (DI FANTI, 2009a, p. 81 - grifo nosso). O destaque ao não vínculo com a estrutura dos enunciados procura dissociar, como aparece na nota explicativa do Dicionário, o diálogo da interação face a face: "o diálogo constitui-se como uma interação viva entre discursos, um diálogo interno, que não se limita à forma composicional do diálogo estrito (face a face), pois é bem mais amplo, diversificado e complexo" (idem). Ao se procurar enfatizar a dialogicidade interna, que estabelece permanente relações de sentido com outros discursos, como consonância, discordância, reiteração, confronto etc., ressalta-se a não limitação presencial, como entendido no senso comum, geralmente voltada para a busca de entendimento/acordo entre partes.

O verbete dialogismo é definido como "princípio da linguagem que pessupõe que todo discurso é constituído por outros discursos, mais ou menos aparentes, desencadeando diferentes relações de sentido" (DI FANTI, 2009b, p. 80). O discurso, sendo constitutivamente dialógico, traz ressonâncias de já-ditos, responde a dizeres diversos (passados, presentes e futuros) e faz projeções e/ou antecipações do discurso-resposta. A preocupação em mostrar o dialogismo como um princípio da linguagem 
deve-se ao entendimento de que o discurso não é isolado, ou seja, todo discurso nasce de um complexo diálogo entre discursos.

Faraco (2009, p. 60-61), em Linguagem \& Diálogo: as ideias linguísticas do Círculo de Bakhtin, refere-se ao diálogo como "essa palavra mil vezes "mal-dita". Observa que a palavra diálogo tem várias significações sociais, que podem afetar a recepção do pensamento do Círculo. Como observa o linguista, Bakhtin criticou a ideia do que chama um "dialogismo estreito", que estaria associado ao "diálogo estrito do termo". As formas clássicas, como conversa de personagens em narrativas, sequência de fala dos personagens em texto dramático, conversação na interação face a face entre outras, não constituem objeto de preocupação quando associadas a relações entre réplicas do diálogo.

Para Bakhtin,

[...] A relação entre as réplicas de tal diálogo é o tipo mais externamente notório e simples de relações dialógicas. Contudo, as relações dialógicas não coincidem, de maneira nenhuma, com as relações entre as réplicas do diálogo real; são bem mais amplas, diversificadas e complexas. (19591961/2003, p. 331)

Discutindo essa questão, Faraco pondera que o evento do diálogo face a face está no foco de atenção do Círculo não como forma composicional, mas sim como "espaço em que mais diretamente se pode observar a dinâmica do processo de interação das vozes sociais" (2009, p. 61).

Essa concepção de diálogo está no cerne do conceito de enunciação/enunciado, que, em Marxismo e filosofia da linguagem (Bakhtin/Volochinov, 1929/1995), é entendido como a materialização da interação social, em um momento histórico, estabelecendo relações de sentido diversos entre contextos. As relações de sentido, para Bakhtin (1929/1997), são relações dialógicas, expressas pelo contato entre variadas vozes sociais provenientes de diferentes sujeitos do discurso, como a resposta a dizeres anteriores e a antecipação de dizeres futuros.

No conjunto das reflexões sobre diálogo a partir da obra bakhtiniana, Faraco (2009, p. 68) questiona: "Diálogo é consenso?" Para desenvolver sua reflexão, observa que, no uso corrente, a palavra diálogo remete a uma avaliação positiva no sentido de "solução de conflitos", "entendimento", "geração de consenso". No entanto, não é essa a compreensão do Círculo de Bakhtin, já que os teóricos não se ocupam com o consenso e nem fazem apologia ao entendimento. Os teóricos do Círculo voltam-se para a "dinâmica das relações dialógicas num contexto social dado e observam que essas relações não apontam apenas na direção das consonâncias, mas também das multissonâncias e dissonâncias" (idem). Assim, vários resultados podem ser gerados pelas relações dialógicas, como convergência, acordo, adesão, divergência, desacordo, recusa etc.

O enunciado, para Bakhtin (1952-1953/2003), sendo constitutivamente dialógico, é considerado um elo na cadeia de comunicação discursiva, o que significa que está ligado ao passado e ao futuro ao mesmo tempo, respondendo e antecipando respostas. Nesse sentido, Faraco $(2009$, p. 59) assinala que todo enunciado é uma réplica, trazendo consigo uma memória discursiva.

Para tratar do PPGL, neste ano comemorativo, passamos a desenvolver reflexões a partir de diferentes relações dialógicas, especialmente no que se refere a importantes eventos inter-relacionados que conectam aspectos do passado e do presente e antecipam questões do futuro. No que tange à memória, parece-nos que o primeiro ponto a ser destacado é a criação do PPGL em 1969 pelo Egrégio Conselho Universitário da PUCRS, sob a denominação de Curso de Pós-Graduação em Linguística e Letras. No ano seguinte, no dia 12 de março de 1970, foi instalado o Curso de Pós-Graduação em Linguística e Letras (CPGLL), com a atribuição de implantar o Programa de Mestrado no Instituto de Letras e Artes (ILA). ${ }^{1}$

Se esse foi o ato fundador do hoje Programa de PósGraduação em Letras, a iniciativa de criá-lo remonta a 1965, quando o ILA, hoje Faculdade de Letras, criou o Centro de Estudos da Língua Portuguesa, sob a direção do Ir. Elvo Clemente. Importantes atividades, como realização de cursos, palestras, treinamentos e publicação de manuais, antecederam a criação do PPGL. A revista Letras de Hoje, criada no ILA, teve seu primeiro número lançado em 1967, resultante do trabalho dos professores Leonor Scliar Cabral, Plínio Cabral e do então diretor da revista, Ir. Elvo Clemente, e vinculou-se ao Programa de Pós-Graduação após sua criação. Essa Revista quadrimestral, com dois números dedicados à Linguística e dois à Literatura por ano, circula regularmente até o presente (fará 50 anos em 2017) e está classificada no mais alto estrato dos periódicos (A1) pelo Qualis/CAPES.

Ainda na recuperação da memória que antecede a criação do PPGL, destaca-se, em 1969, o oferecimento do primeiro curso de especialização em Linguística. O curso foi ministrado pela docente Leda Bisol, atualmente professora do quadro permanente do Programa, que seguiu orientação dos mestres Joaquim Mattoso Câmara Jr., Ursula Wiesemann, Brian Head e Arion Dall'Igna Rodrigues.

\footnotetext{
Os dados referentes ao histórico do PPGL foram retirados do Catálogo do Curso de Pós-Graduação em Letras, CPGL-PUCRS (1992), organizado por Maria Eunice Moreira e Vera Teixeira de Aguiar, e do site do PPGL (http://www3.pucrs.br/portal/page/portal/faleppg/ppgl).
} 
O PPGL iniciou suas atividades em 1970, com o Mestrado na área de Linguística Aplicada (atual Linguística), tendo o professor Ir. Elvo Clemente como primeiro coordenador. Em 1972, expandiu suas atividades ao estabelecer uma nova área, a Teoria Literária (atual Teoria da Literatura). Em 8 de outubro de 1973, o Curso foi credenciado pelo Conselho Federal de Educação, via Parecer $843 / 73$, passando a desenvolver atuação pioneira no Estado do Rio Grande do Sul.

Desde a criação do PPGL, antes Curso de PósGraduação em Linguística e Letras, podem-se identificar três fases, decorrentes do seu amadurecimento e do diálogo com as diretrizes da CAPES, que estão articuladas na composição do Programa. Na primeira, entre 1970 e 1977, o impacto do PPGL foi mais regional, acolhendo majoritariamente alunos de Instituições do Estado do Rio Grande do Sul e capital. Também frequentavam o curso docentes de outros Estados brasileiros, como Ceará, Maranhão, Pará e Pernambuco. Pesquisas e eventos visavam sobretudo à realidade social sul-rio-grandense, por isso diversos trabalhos (publicações, dissertações) desenvolviam temas predominantemente sobre a cultura local. Desde a criação, o Programa contou com um corpo docente de renome internacional, como Landon Lockett e Petrona Rodriguez-Pasqués, além de valer-se da colaboração de professores eméritos, como Paulino Vandresen e Leonor Scliar Cabral. Em 27 de abril de 1977, o Conselho Universitário da PUCRS aprovou a criação do nível de Doutorado, nas áreas de Linguística Aplicada e Teoria da Literatura, cujas atividades tiveram início em 1978. O Curso, em nível de Mestrado e de Doutorado, foi credenciado pelo Conselho Federal de Educação em 5 de dezembro de 1985, através do Parecer 864/85, e recredenciado em 7 de outubro de 1993, pelo Parecer 639/93.

No que tange à segunda fase, de 1978, início do Doutorado, a 2004, o PPGL teve uma grande ampliação, que pode ser observada pela contratação de professores estrangeiros de Linguística (Feryal Yavas e Mehmet Yavas) e pelo ingresso de alunos das cinco regiões brasileiras, que fizeram pesquisas relevantes para seus Estados. Nesse cenário, o Programa contribuiu para a expansão da pós-graduação brasileira, como pode se perceber pela alocação dos egressos em diferentes Programas stricto sensu de Instituições de Ensino Superior e pela divulgação e produção intelectual em eventos e publicações. Nessa fase, a Linguística voltou-se para Psicolinguística, Sociolinguística e Teoria da Variação, Texto e Discurso, Lógica da Linguagem Natural, Fonologia, Sintaxe e Semântica. A Teoria da Literatura optou pela avaliação crítica da produção e recepção literárias; recuperação e historicização da memória literária; sistema literário de língua portuguesa e de outras línguas; teorias da leitura e formação do leitor infantil e juvenil.
Foi na segunda fase, em 1985, que surgiu a Oficina de Criação Literária, voltada para incentivar a produção artística de novos autores. Com reputação nacional, a Oficina, ministrada pelo escritor e professor do PPGL Luiz Antonio de Assis Brasil até a atualidade, já formou mais de 800 alunos de vários Estados, muitos com projeção nacional ${ }^{2}$.

No que diz respeito à terceira e atual fase do PPGL, iniciada em 2004 com a posse do Reitor Joaquim Clotet e com a implantação do Plano Estratégico da PUCRS (5 grandes áreas: ensino, pesquisa, extensão, ações comunitárias e desenvolvimento institucional e meio ambiente), o Programa registrou avanço do conhecimento, contribuindo para o desenvolvimento científico. A nova visão da PUCRS exigiu a reestruturação do Programa em 2008, para enfrentar desafios no contexto acadêmico e social contemporâneos, com objetivos de (a) fortalecer aspectos positivos que asseguraram a posição do PPGL nacional e internacionalmente e (b) adequar-se às novas exigências da pós-graduação, sobre produção de conhecimento e qualificação docente. A reformulação, discutida pelos docentes, manteve a estrutura básica que vinha orientando o PPGL, mas inovou ao criar espaço de discussão entre as áreas, apoiado em uma linha de pesquisa comum - Fundamentos Linguístico-Literários da Linguagem - que associa Linguística e Literatura ao estudo de teorias do campo abrangente da linguagem.

A área de Teoria da Literatura, de 2006 a 2011, expandiu-se ao instituir o acolhimento de alunos da escrita literária, e reservou três vagas do mestrado em Teoria da Literatura aos que pretendessem elaborar trabalho criativo. O diferencial era o trabalho de conclusão, que deveria conter, além da criação literária, um ensaio sobre o processo criativo. A primeira defesa de mestrado nessa modalidade foi em 2008, e a primeira defesa de tese de doutorado ocorreu em 2010.

Em 2011, com 12 mestrados e 1 doutorado concluídos, o PPGL propôs a criação da área de Escrita Criativa, aprovada em 30 de junho, pela Câmara de Pós-Graduação da PUCRS. A área iniciou em 2012 com disciplinas sobre o processo criativo e bases teóricas. Fundamentada em sólida caminhada em criação textual, ampliou o espectro do trabalho final, acolhendo não somente criação literária, mas outras formas de trabalho criativo. A nova área credenciou docentes da Comunicação, Filosofia e História da PUCRS, favorecendo a interdisciplinaridade. Ao criar a área de Escrita Criativa, sem precedentes no Brasil, o PPGL dava visibilidade ao que já vinha realizando com a Oficina Literária desde 1985 e às orientações concluídas na área. Nessa nova área, ocorreu, em dezembro de 2012,

\footnotetext{
2 Citamos alguns: Cíntia Moscovich, Letícia Wierzchowski, Michel Laub, Daniel Galera e Amilcar Bettega Barbosa.
} 
a defesa de doutorado, em cotutela, com dupla titulação, de Amílcar Bettega Barbosa, orientada pela professora Jacqueline Penjon, da Université Paris 3, e pelo professor Assis Brasil, da PUCRS.

Com a nova área de Escrita Criativa, o Programa de Pós-Graduação em Letras da PUCRS passou, então, a ter três áreas de concentração: Linguística, Teoria da Literatura e Escrita Criativa. A Linguística, comprometendo-se com análise e descrição de sistemas e do uso da língua, possui duas linhas de pesquisa: Teoria e Análise Linguística e Teorias e Uso da Linguagem. A Teoria da Literatura volta-se a questões relativas a aspectos teórico-críticos da produção e recepção literárias, sistema literário, formação de leitores, pesquisa sobre fontes primárias, recuperação e história da literatura. Nessa área, há duas linhas de pesquisa: Teorias Críticas da Literatura e Literatura, História e Memória. A Escrita Criativa, com ênfase interdisciplinar, tem uma linha de pesquisa específica: Leitura, Criação e Sistema Literário. Investiga a gênese de textos literários e não literários, sua relação com outras linguagens, a inclusão do escritor no sistema literário, apoiada em teorias críticas da literatura e em documentos de escritores sobre o processo de criação, disponíveis no DELFOS - Espaço de Documentação e Memória Cultural. As três áreas têm em comum uma linha de pesquisa - Fundamentos Linguístico-Literários da Linguagem - que proporciona o estabelecimento de estudos interdisciplinares e dá suporte ao estudo teórico do significado nos textos literários e não literários, tendo como foco a linguagem. ${ }^{3}$

$\mathrm{Na}$ fase atual, emergem resultados dos diversos diálogos empreendidos ao longo dos 45 anos do PPGL. Os resultados podem ser observados nas estruturas de pesquisa do Programa que conta com três Centros: Centro de Estudos Linguísticos (CELING), Centro de Estudos Literários (CELIT) e Centro de Referência para o Desenvolvimento da Linguagem (CELIN). Os Centros são constituídos por 13 Núcleos de Pesquisa, que por sua vez aglutinam os Grupos de Pesquisa, coordenados por professores do Programa e certificados pelo CNPq. ${ }^{4}$

O PPGL, em constante análise de seus processos, considerando as orientações da CAPES e em consonância com a política de pós-graduação e pesquisa da PUCRS, tomou importantes iniciativas, no triênio 2010-2012, visando à excelência do Programa. Propôs em 2011 um Plano Estratégico, de modo a diagnosticar e a apontar soluções para os problemas enfrentados. Também reviu o processo de credenciamento e recredenciamento docente, atentando para as métricas de produção qualificada e para

\footnotetext{
3 Para maiores informações sobre as áreas de concentração e as linhas de pesquisa, consultar o site do PPGL: <http://www3.pucrs.br/portal/page/ portal/faleppg/ppgl/ppglApresentacao>.

4 Para maiores informações, consultar o site do PPGL: <http://www3. pucrs.br/portal/page/portal/faleppg/ppgl/ppglApresentacao $>$.
}

a contratação de professores por seleção pública. Com as contratações, efetuadas desde 2009, o corpo docente manteve, em sua composição, professores seniores, em fase intermediária da carreira e em fase inicial. Na dimensão do corpo discente, o Programa incorporou, em 2012, a prova escrita para a seleção de doutorado, almejando também qualificar o ingresso de doutorandos no PPGL.

Intensificaram-se, nesta terceira fase, a produção científica contínua de qualidade dos professores, no Brasil e no exterior, e a qualificação docente, via pósdoutoramento, conforme a política da PUCRS, que estimula a saída de um docente/semestre em cada Programa, o que resultou no cômputo de $73 \%$ professores com pós-doutorado em 2014.

Um dos principais diferenciais do PPGL, no período, foi o fortalecimento das ações de cooperação não só em nível nacional, mas também em nível internacional. No cenário nacional, destacam-se importantes ações com o apoio da CAPES: dois PROCADs (2008-2012) e um DINTER (2010-2014). Um PROCAD foi estabelecido com a UNESP (Assis), a UFG e a UEM; o outro com a UNEB. O DINTER foi uma parceria com o Programa de Pós-Graduação em Estudos de Linguagem da UNEB e titulou 20 doutores, professores de diversos campi da Universidade baiana. Entre as universidades brasileiras, com as quais o PPGL mantém parcerias constantes de trabalho, destacam-se: UFRGS, UCPel, UFPel, FURG, PUC-SP, UNISINOS, UFSM, UnB, UPF, UERJ, UNIFESP, UFU, UNEB, UFPA, UFRN, UFF.

Os principais convênios e parcerias internacionais desenvolvem-se com as seguintes Universidades: Universidade de Lisboa, Universidade Aberta de Portugal, Universidade dos Açores, Universidade do Porto, Universidad de Barcelona, Université de la Sorbonne Nouvelle - Paris 3, Université Sorbonne- Paris 4, Université Michel de Montaigne, Bordeaux 3, Institut de Textes et Manuscrits Modernes (ITEM - Paris), École des Hautes Études en Sciences Sociales de Paris, AixMarseille Université, Vrije Universiteit Amsterdam, University of China e Universidad de Chile. Essas e outras parcerias têm possibilitado a acolhida de nossos docentes em estágio pós-doutoral; doutorandos em estágios de bolsa-sanduíche; publicações conjuntas, a exemplo da Revista Navegações com a Universidade de Lisboa, tendo por editoras as professores Vania Pinheiro Chaves da UL e Maria Eunice Moreira da PUCRS; pesquisas conjuntas, como a desenvolvida com a Universidade de Lisboa sobre o Almanaque de Lembranças Luso-Brasileiro (18501932), envolvendo doutorandos e docentes da PUCRS; e a participação de Marie-Hélène Paret Passos na equipe do ITEM Multilinguisme - Transfers - Création. Destacam-se também as cotutelas de teses, com dupla titulação, dentre as quais a tese em andamento de Cécile Jacquey, 
da Université Michel de Montaigne, Bordeaux 3, a ser defendida na França; a tese de Bruno Mazolini de Barros, da PUCRS/Bordeaux, e a tese de Rafael Costa Mendes, da PUCRS/Paris 3.

O Programa tem recebido muitos professores estrangeiros na condição de visitantes para ministrarem cursos, atuarem como pesquisadores e coorientadores de dissertações e teses, entre os quais destacam-se Carlos Reis, da Universidade de Coimbra, e Leo Wetzel, da Vrije Universiteit Amsterdam, ambos com título de Doutor Honoris Causa pela PUCRS. Neste ano comemorativo dos 45 anos, o PPGL recebeu, no primeiro semestre, na condição de visitante, com apoio do $\mathrm{CNPq}$, a professora Anna Caballé, da Universidad de Barcelona, para ministrar disciplina para mestrandos e doutorandos. Também ofereceu uma Escola de Altos Estudos (CAPES) com a pesquisadora Evelyn Ferstl, do Center for Cognitive Science, da Universidade de Freiburg, Alemanha. No segundo semestre, três professores ministraram cursos no Programa com apoio do CNPq: Ana Maria Binet (Université Michel de Montaigne, Bordeaux 3), Yves Schwartz (Aix-Marseille Université, da França) e Janet Paterson (Universidade de Toronto, do Canadá).

Assim, as relações internacionais com reciprocidade na realização de eventos, publicações, intercâmbio de docentes e discentes, coorientação e cotutela de teses foram fortemente intensificadas nos últimos anos. Também houve um crescimento do número de doutorandos em estágio-sanduíche no Exterior, alcançando uma média, entre 2010 e 2012, de 9 por ano, sendo que a maioria dos estágios ocorreu em universidades parceiras do PPGL, conforme mencionado acima, o que fortaleceu a cooperação e a internacionalização do Programa. ${ }^{5}$

Na ficha de avaliação do PPGL, referente à Apreciação do resultado da Avaliação Trienal 2013 (período: 20102012), importantes pontos foram destacados:

O Programa de Letras e Linguística da PUCRS apresenta uma proposta coerente que demonstra associação entre tradição e renovação, já que sua equipe, em constante formação, está sempre atenta aos pontos a serem revisados e/ou incorporados para o desenvolvimento dos cursos. Trata-se de um programa consolidado com forte impacto na formação de docentes e pesquisadores no país com nucleação nas diferentes regiões. Isso porque, além do trabalho intra-muros, tem-se articulado com outras instituições de ensino superior em parcerias como Procad, Minter e Dinter, e com outras instituições educacionais com atuação em outros níveis de ensino. A internacionalização progressiva ocorre com convênios com diversas universidades estrangeiras, o que acentua o trânsito de docentes e discentes bem como o intercâmbio de experiências. $\mathrm{O}$ número de titulados, o tempo de permanência dos discentes, a maior parte de bolsistas assim como a produção bibliográfica do Programa atestam a significativa produtividade do curso. (grifo nosso) ${ }^{6}$

No campo dos diferentes diálogos empreendidos pelo PPGL, que resulta em uma complexa composição, ter o reconhecimento da CAPES na qualidade do Programa e na pertinência da integração entre tradição e renovação é um estímulo para a contínua busca pela excelência. Nesse sentido, ainda em 2013, foi definido um Plano de Consolidação da nota 6 e criado um Plano de Renovação de Bolsas para mestrandos e doutorandos. Também foi realizada uma revisão na estrutura curricular do Programa, com vistas a atender às exigências atuais da formação dos pós-graduandos. A partir de 2013, com o apoio da PUCRS, o PPGL passou a oferecer disciplinas em língua estrangeira (inglês e francês) e em 2015 teve a publicação da versão do site em língua inglesa.

Neste ano comemorativo aos 45 anos do PPGL, três eventos internacionais se destacam: o II Encontro Internacional de Sintaxe, Semântica e suas Interfaces, o XI Seminário Internacional de História da Literatura, que vem sendo realizado desde 1995, e o Dialogue Under Occupation (DUO VII).

Este número especial da revista Letras de Hoje, respondendo a interlocuções do passado, interagindo com questões do presente e antecipando respostas a devir, registra diferentes diálogos, seja em relação a questões de pós-graduação e pesquisa, seja em relação ao tema do DUO VII, às pesquisas em desenvolvimento e às parcerias interinstitucionais.

Os artigos que constituem este volume, assinados por renomados pesquisadores brasileiros e estrangeiros, contemplam as áreas de Linguística, Teoria da Literatura e Escrita Criativa, bem como outras áreas das Ciências Humanas. Os textos discutem questões relativas a linguagem, enunciação, diálogo, ideologia, identidade, alteridade, atividade, americanidade, transnacionalidade, alienação, capitalismo, e apresentam reflexões instigantes para o leitor, desencadeadas por questões cruciais a respeito de interação humana, conflito, superação, confirmando a necessidade de diálogo entre as áreas de conhecimento e mesmo de uma transdiciplinaridade que contribua para estabelecer estratégias de convívio e respeito humanos, de diálogos culturais que compartilhem saberes, dando voz a todos.

\footnotetext{
5 Consulte os Dados do PPGL, referentes à Internacionalização e a Intercâmbios, na Plataforma Sucupira: <https://sucupira.capes.gov.br/ sucupira/public/consultas/coleta/envioColeta/dadosEnvioColeta.jsf $>$.

6 A última Avaliação Trienal do PPGL, correspondente ao período compreendido entre 2010 e 2012, pode ser conferida no site: <http:/ conteudoweb.capes.gov.br/conteudoweb/ProjetoRelacaoCursosServ let? acao $=$ detal hamentoIes \& codigoPrograma $=42005019009 \mathrm{P} 1 \&$ desc ricaoGrandeArea $=$ LING $\%$ DC $\%$ CDSTICA $\% 2 C+$ LETRAS $+E+A R T$ ES $+++++++++++++++++++++++++++++++++\&$ descricaoAreaConh ecimento $=\mathrm{LING} \% \mathrm{DC} \% \mathrm{CDSTICA}>$.
} 


\section{Referências}

[Avaliação Trienal 2013 do PPGL, CAPES]. Disponível em: $<$ http://conteudoweb.capes.gov.br/conteudoweb/ProjetoRe lacaoCursos Servlet?acao=detalhamentoIes\&codigoProgra $\mathrm{ma}=42005019009 \mathrm{P} 1 \&$ descricaoGrandeArea $=\mathrm{LING} \% \mathrm{DC} \%$ CDSTICA $\% 2 \mathrm{C}+\mathrm{LETRAS}+\mathrm{E}+\mathrm{ARTES}++++++++++++++-$ $+++++++++++++++++++\&$ descricaoAreaConhecimento $=\mathrm{LI}$ NG\%DC\%CDSTICA>. Acesso em: 10 out. 2015.

BAKHTIN, M. Problemas da poética de Dostoiévski (1929/ 1963). Trad. Paulo Bezerra. 2. ed. Rio de Janeiro: Forense Universitária, 1997.

BAKHTIN, M. O problema do texto na linguística, na filologia e em outras ciências humanas (1959-1961). In: BAKHTIN, M. Estética da criação verbal (1979). Trad. Paulo Bezerra. 4. ed. São Paulo: Martins Fontes, 2003.

BAKHTIN, M. Os gêneros do discurso (1952-1953). In: BAKHTIN, M. Estética da criação verbal (1979). Trad. Paulo Bezerra. 4. ed. São Paulo: Martins Fontes, 2003.

BAKHTIN, M.; VOLOCHINOV, V. N. Marxismo e filosofia da linguagem: problemas fundamentais do método sociológico na ciência da linguagem (1929). Trad. Michel Lahud e Yara Frateschi Vieira. 7. ed. São Paulo: Hucitec, 1995.
[Coleta 2014 - Plataforma Sucupira]. Disponível em: <https:// sucupira.capes.gov.br/sucupira/public/consultas/coleta/ envioColeta/dadosEnvioColeta.jsf>. Acesso em: 12 out. 2015.

[Delfos]. Disponível em: <http://www.pucrs.br/delfos/?p= capa>. Acesso em: 12 out. 2015.

DI FANTI, M. G. C. Diálogo. In: FLORES, V. N.; BARBISAN, L. B.; FINATTO, M. J. B.; TEIXEIRA, M. Dicionário de linguística da enunciação. São Paulo: Contexto, 2009a.

DI FANTI, M. G. C. Dialogismo. In: FLORES, V. N.; BARBISAN, L. B.; FINATTO, M. J. B.; TEIXEIRA, M. Dicionário de linguística da enunciação. São Paulo: Contexto, 2009.

FARACO, C. A. Linguagem \& diálogo: as ideias linguísticas do Círculo de Bakhtin. São Paulo: Parábola Editorial, 2009.

[Programa de Pós-Graduação em Letras da PUCRS]. Disponível em: <http://www3.pucrs.br/portal/page/portal/faleppg/ppgl>. Acesso em: 10 out. 2015.

MOREIRA, M. E.; AGUIAR, V. T. (Org.). Catálogo do Curso de Pós-Graduação em Letras. CPGL-PUCRS, 1992.

Recebido: 20 de setembro de 2015

Aprovado: 15 de outubro de 2015

Contato: gloria.difanti@pucrs.br ana.lisboa@pucrs.br lilian.hubner@pucrs.br 